ГОРЮНОВА Анна Андреевна - лаборант-исследователь международной междисциллинарной научно-исследовательской лаборатории изучения мировых и социально-политических процессов, аспирант Нижегородского государственного лингвистического университета им. Н.А. Добролюбова (603155, Россия, Нижний Новгород, ул. Минина, 31a, asukhanova@list.ru)

\title{
ВЛИЯНИЕ АНТИРОССИЙСКИХ САНКЦИЙ НА ВЫПОЛНЕНИЕ ЗАДАЧ, СТОЯЩИХ ПЕРЕД ОБОРОННО-ПРОМЫШЛЕННЫМ КОМПЛЕКСОМ РОССИИ
}

\begin{abstract}
Аннотация. Статья посвящена исследованию влияния антироссийских санкций на выполнение задач, поставленных государством перед ОПК РФ. Автор рассматривает научный подход к данному вопросу, а также данные, полученные в ходе исследования. Анализ полученной информации привел к выводу, что санкции изменили ситуацию в отрасли: поставленные государством задачи выполняются, но требуют дополнительных ресурсов.
\end{abstract}

Ключевые слова: санкции, ОПК, ГОЗ, импортозамещение, оборонная продукция, государственная поддержка

$\mathrm{O}$ боронно-промышленный комплекс (далее - ОПК) является одним из крупнейших секторов экономики РФ. Цели и задачи, стоящие перед ним, определяет государство в соответствии с потребностями внутренней и внешней политики. Эффективность выполнения задач, стоящих перед ОПК, имеет значение не только внутри страны, но и на внешнеполитической арене.

Присоединение Крыма в 2014 г. повлекло за собой многие значимые события, в т.ч. и наложение санкций как на отдельных лиц, организации, так и на Россию в целом.

Санкции к России начали применять с 2014 г. на трех уровнях.

1. Санкции на дипломатическом уровне: предполагают усложнение визового режима, приостановление договоров по партнерским отношениям и по взаимным инвестициям между странами. Обострились отношения с НАТО, $G 8$ исключила Россию из числа стран-участниц, ОЭСР заморозила процесс присоединения к своему составу.

2. Санкции в отношении физических лиц (политиков, чиновников, государственных и военных деятелей, бизнесменов): предполагают запрет на въезд россиян в ряд стран и заморозку зарубежных активов этих людей.

3. Экономические санкции: направлены среди прочих на ОПК. На этом уровне были затронуты корпорация «Ростех» и концерн «Алмаз-Антей», «Сириус», «Станкоинструмент», «Калашников», «Тульский оружейный завод», НПО «Восточные комплексы», «Добролет». Запрет долгового финансирования коснулся Уралвагонзавода, Оборонпрома, Объединенной авиастроительной корпорации и др. Введен запрет на торговлю оружием с РФ, продажу продукции двойного назначения военным клиентам, прекращены поставки вооружений и финансирование для закупок оружия, запрешен экспорт в Россию товаров и технологий, «чувствительных» с точки зрения национальной безопасности США, запрещена продажа РФ такой номенклатуры, как станки и оборудование, приборы ночной видимости, беспилотные летательные аппараты, элементная база для производства интегральных микросхем [Бревнов 2016], и др., что нанесло значительный ущерб ОПК России.

Таким образом, действия стран, которые ввели антироссийские санкции, 
привели к усложнению процесса выполнения ГОЗа, а это является важнейшим условием обеспечения безопасности страны, контролируется президентом и имеет закрепленную уголовную ответственность за ненадлежащее исполнение.

Санкции обходят стороной отрасль космонавтики; США не отказываются от сотрудничества с Россией в этой сфере и используют «Союз» для доставки своих космонавтов на борт МКС.

Сложившаяся ситуация сформировала новую политическую и экономическую реальность, новый мировой порядок, оказывающий большое влияние как на развитие страны в целом, так и на субъекты ОПК в частности. В связи с тем, что ОПК является важнейшим сектором в экономике страны, данные события привели к значимым количественным и качественным изменениям в его структуре, в характере диалога между странами -покупателями и странами - продавцами вооружения, поддержавшими и не поддержавшими санкции.

В этом контексте важно изучить задачи, которые государство ставит перед рассматриваемым сектором. На официальном сайте Минпромторга выделены следующие задачи ОПК ${ }^{1}$ :

1) реализация мероприятий по импортозамещению комплектующих изделий, сырья и материалов;

2) обеспечение Вооруженных сил РФ военной и специальной техникой для реализации заданий в области развития ОПК;

3) совершенствование нормативной базы по стандартизации оборонной продукции;

4) реализация мероприятий по обеспечению устойчивого развития экономики и социальной стабильности;

5) выявление и оперативное рассмотрение факторов финансово-экономического и социального характера, оказывающих негативное влияние на деятельность организаций ОПК;

6) выработка мер государственной поддержки для стабилизации ситуации на предприятиях ОПК и решения общесистемных проблем для отраслей ОПК;

7) развитие производства профильной высокотехнологичной гражданской продукции, развитие в этих целях инновационной инфраструктуры ОПК;

8) повышение кадрового потенциала, его соцподдержка.

Таким образом, некоторые задачи напрямую связаны с необходимостью минимизации последствий санкционного преследования России, в то время как остальные направлены на долгосрочное развитие ОПК РФ.

Система мер реагирования российского руководства на антироссийскую санкционную политику зарубежных стран предполагала реализацию программ импортозамещения, а также введение дополнительных НПА и прочих мер, что помогло смягчить удар по экономике страны, и в настоящее время уже можно говорить об определенных результатах проведения данной политики [Аксенов 2019].

\section{Положительные результаты.}

1. Выход на новые внешние рынки. Постановление Правительства РФ от 10 мая 2019 г. о реэкспорте российского вооружения упростило порядок перепродажи российского вооружения в третьи страны, что особенно значимо для стран Африки, Азии и Латинской Америки ${ }^{2}$. Эта мера стала реакцией на закон CAATSA, подписанный Д. Трампом 2 августа 2018 г., налагающий санкции на

1 https://minpromtorg.gov.ru/activities/industry/siszadachi/oboronprom/\# (проверено 28.02.2021).

2 Россия нашласпособ обхода санкций СШАпри продаже оружия. - Ведомости. 15.05.2019. Доступ: https://www.vedomosti.ru/politics/articles/2019/05/14/801357-rossiya-sposob-obhodasanktsii (проверено 28.02.2021). 
покупателей российского оружия. Несмотря на то что мера финансово поддерживает многомиллионный экспорт России, в ней есть определенные риски с точки зрения безопасности.

2. Появление новых торговых партнеров. Несмотря на санкции, география военно-технического сотрудничества постоянно расширяется, среди торговых партнеров России более 100 государств. Несмотря на санкции, Россия в исследовании SIPRI за 2015-2019 гг. сохранила свое место в списке 5 крупнейших экспортеров оружия в мире: доля России составляет $21 \%$ общемирового экспорта, в то время как США - 36\%, Франции - 7,9\%, Германии $-5,8 \%$ и Китая $-5,5 \% 1$. При этом основными покупателями, на которых суммарно приходится 55\% российского экспорта вооружения, являются Индия, Китай и Алжир. Однако, несмотря на это, общий объем экспорта вооружения за период 2015-2019 гг. стал меньше соответствующего показателя за период 2010-2014 гг. на $18 \%$. Таким образом, внешнеполитическая обстановка и антироссийские санкции привели к изменению структуры мирового экспорта, перераспределению доходов и увеличению международных закупок у Франции (рост на 72\%), Израиля (на 77\%) и Южной Кореи (на 143\%).

3. Снижение зависимости от импортных поставок, что стало возможным по итогам работы в рамках реализации программ импортозамещения.

4. Увеличение эффективности системы ГОЗа за период с 2012 по 2017 г. Уровень его выполнения увеличился с $80 \%$ до 97\%, оснащенность армии новой техникой и вооружением повысилась в 3,7 раза² 2

Отрицательные результаты.

1. Девальвация рубля. Несмотря на общее негативное влияние, положительный момент заключается в том, что при значительной роли экспорта вооружения в пополнении бюджета РФ слабый курс рубля играет на руку экспортерам вооружения.

2. Разрыв укрепившихся связей с международными партнерами. Многие европейские компании столкнулись с трудностями кооперации с Россией. В конце 2019 г. власти США потребовали остановить работы по международному проекту «Северный поток - 2», который на тот момент был завершен на $93 \% 3$. Также разрыв отношений с Украиной привел к остановке поставки запчастей для межконтинентальных баллистических ракет Р-36М2 «Воевода», системы наведения и управления ракет УР-100Н, «Рокот», «Тополь», двигателей для самолетов, вертолетов, крылатых ракет, авиационных тактических ракет, корабельных ракет, систем наведения для танков, самолетов и зенитных ракетных комплексов, элементов противотанковых комплексов и др. [Бревнов 2016].

В методологическом плане при рассмотрении проблемы влияния антироссийских санкций на выполнение задач, стоящих перед ОПК РФ, следует обратиться к анализу имеющихся точек зрения российских ученых и специалистов рассматриваемой области на способы минимизации негативных последствий этих проблем.

Исследованием результатов влияния санкций на ОПК РФ занимались различные ученые. Согласно исследованиям, импортозамещение осуществляется в России медленно, но уверенно. В 2014 г. поставки транзисторов, микросхем,

1 Trends in international arms transfers, 2019. March 2020. URL: https://www.sipri.org/sites/ default/files/2020-03/fs_2003_at_2019.pdf (accessed 28.02.2021).

2 Отчет правительства о результатах деятельности за 2012-2017 годы. Доступ: http://static. government.ru/media/files/A7VAAeFNsJuhiJk6lizjPYsGYZn2jfU0.pdf (проверено 28.02.2021).

3 «Удар по Европе»: как в Германии защищают «Севпоток-2» от США. - Газета.ру. 01.07.2020. Доступ: https://www.gazeta.ru/business/2020/07/01/13137475.shtml (проверено 28.02.2021). 
интегральных схем в производстве российского вооружения составляли до 90\%, при этом основными поставщиками являлись западные страны, которые ввели в отношении России санкции ${ }^{1}$. В космической отрасли отсутствие зарубежных комплектующих уже не является критичным. Что касается устойчивого развития отрасли и ее места в экономике страны, то локомотивом процесса развития ОПК должно стать развитие инновационного потенциала. Для этого государству необходимо провести модернизацию предприятий для повышения роли рыночных механизмов с целью увеличения НИОКР, которые в дальнейшем приведут к созданию конкурентного преимущества выпускаемой отечественной продукции перед зарубежными аналогами [Нуреев, Бусыгин 2017]. Можно также использовать отечественные консалтинговые агентства и научно-исследовательские центры, которые могут рассмотреть ситуацию под разными углами зрения. Формирование производственных кластеров и технопарков, которые объединят компании ОПК, металлургию, электростанции и научные центры, даст возможность сократить издержки и оперативно решить производственные задачи. Развитие международного сотрудничества в международном масштабе при грамотном соблюдении норм права в области сохранения интеллектуальной собственности даст новый виток развития ОПК в России.

В части выполнения задачи по государственной поддержке предприятий, как отмечает Р.С. Нуреев, финансовое состояние предприятий ОПК связано с завязкой на государственных заказах, которые определяются государственной политикой и быстро меняющимся положением РФ на международной арене. Убыточность некоторых оборонных предприятий и низкие показатели финансовой эффективности исследователь связывает с низким качеством управления. Путь повышения финансовой стабильности видится в модернизации ОПК с целью усиления рыночных стимулов.

Значительную роль в поддержке ОПК России сыграл федеральный закон «О промышленной политике в Российской Федерации» № 488-Ф3, принятый 31.12.2014, который среди прочего направлен на стимулирование инвестиций в проекты по импортозамещению, что, как отмечают исследователи, приведет к модернизации отрасли, производству более конкурентоспособного вооружения [Базилевский, Злобин 2017].

В сентябре 2020 г. было закончено исследование, проведенное на базе нижегородского оборонного предприятия АО «ФНПЦ «ННИИРТ», на основании результатов которого по вопросу решения задач, стоящих перед ОПК, можно сделать следующие выводы.

1. Проблема импортозамещения, появившаяся в связи с зарубежными санкциями, стала вызовом для компаний отрасли. Резкое переориентирование на отечественную элементную базу при сохранении сроков выполнения изделий по ГОЗу с серьезной проверкой качества на этапе его военной приемки создало значительные проблемы на многих уровнях производства, потребовало решения проблем в сфере разработки на производственном и управленческом уровне.

2. Задача по оснащению ВС РФ требуемыми изделиями осуществляется в рамках ГОЗа. Как отмечает руководство исследуемого предприятия, ни пандемия коронавируса, ни антироссийские санкции, ни усложнение ситуации на международной арене не умаляют требования выполнения ГОЗа, а, наоборот,

\footnotetext{
1 Ученые: в российском вооружении 90\% западной электроники. - Газета ру. 31.10.2014. Доступ: https://www.gazeta.ru/science/news/2014/10/31/n_6611725.shtml (проверено 28.02.2021).
} 
только усиливают необходимость тщательного исполнения сроков выполнения работ.

3. Задача по совершенствованию нормативной базы по стандартизации оборонной продукции выполняется в рамках соответствующих требований. На исследуемом предприятии все нормативы в этой сфере выполнены.

4. Выполнение задачи реализации мероприятий по обеспечению устойчивого развития экономики и социальной стабильности страны руководство исследуемого предприятия видит в том, чтобы качественно и своевременно выполнять поставленные перед ним задачи.

5. Говоря о факторах финансово-экономического и социального характера, негативно влияющих на деятельность изучаемого предприятия, на микроуровне в 2020 г. можно особо выделить пандемию коронавируса, а на макроуровне - серьезную нехватку государственных инвестиций, выделяемых на поддержку и развитие науки. Во многом эта проблема на макроуровне объясняется тем, что исследуемое предприятие является научно-производственным центром в наукоемкой отрасли, и работа в области научно-исследовательских и опытно-конструкторских разработок является его основным видом деятельности. Полученная в ходе исследования информация соответствует данным Global R\&D Funding Forecast 2016 о том, что доля российских инвестиций в НИОКР в мировом масштабе составляла лишь $1 \% 1$, а в 2019 г. $-2,7 \%$, или 64,5 млрд долл. США², в то время как в США этот показатель в 2019 г. был равен 25,2\%, или 596,6 млрд долл. США. Более того, убыточность и низкие финансовые показатели некоторых предприятий, которые другие исследователи считают следствием слабого управления, руководители рассматриваемой организации анализируют как отражение превышения расходов (и на научную деятельность в том числе) над доходами. Наукоемкие производства очень затратны, а расходы на этот вид деятельности окупаются в течение нескольких лет, а иногда и не окупаются вообще. Но именно расходы на НИОКР способны привести к созданию прорывных технологий.

6. По вопросу выработки мер государственной поддержки для стабилизации ситуации на предприятиях ОПК и решения общесистемных проблем на исследуемом предприятии осуществляются мероприятия в рамках федеральных целевых программ, курируемых отраслевым министерством (Минпромторг), направленных на развитие и внедрение прорывных технологий.

7. Выполнение мероприятий по развитию производства профильной высокотехнологичной гражданской продукции в видении руководства исследуемого предприятия является сложной задачей. Во-первых, это обусловлено особенностями предприятия, его структурой, направленностью на научные исследования в области слежения и обнаружения объектов, политикой закупочной деятельности с высочайшими требованиями к качеству изначального сырья, материалов и комплектующих. Во-вторых, изделия военного назначения часто уникальны, не имеют аналогов, и их стоимость не может определяться рыночным принципом. В-третьих, сложившаяся геополитическая обстановка, введение политических и экономических санкций не располагают к переориентации с оборонного аспекта деятельности на производство продукции гражданского назначения. Перестраиваться под быстро меняющуюся конъюнктуру рынка предприятиям с несколькими тысячами сотрудников сложно. Политика пере-

1 Global R\&D Funding forecast 2016. URL: https:/www.iriweb.org/sites/default/files/2016Glo balR\%26DFundingForecast_2.pdf (accessed 28.02.2021).

2 Global R\&D Funding forecast: Special mid-year update, part 1. URL: https://www. rdworldonline.com/global-rd-funding-forecast-special-mid-year-update-part-1/ (accessed 28.02.2021). 
ориентации военного предприятия на гражданские рельсы уже показала свою неэффективность во времена М.С. Горбачева, и если и применима в современных реалиях, то не для каждого предприятия ОПК. Таким образом, задача производства гражданской продукции на базе предприятий ОПК достаточно сложная, но работа в данном направлении ведется.

8. Выполнение задачи повышения кадрового потенциала предприятий ОПК, его соцподдержки осуществляется в рамках коллективного договора. Он предполагает социальную поддержку, а также меры по стимулированию научной деятельности сотрудников и пр.

Таким образом, антироссийские санкции нанесли определенный ущерб сектору ОПК РФ. Выполнение поставленных государством перед сектором задач осуществляется, но требует дополнительных ресурсов. Научное сообщество видит решение большинства проблем в модернизации отрасли, его государственной поддержке и развитии научной деятельности.

\title{
Список литературы
}

Аксенов И.А. 2019. Санкционная политика США и стран Западной Европы в отношении России. Экономика: проблемы, решения и перспективы. Вестник Университета. № 10. С. 147-151.

Базилевский А.И, Злобин Е.Ф. 2017. Перспективы развития оборонно-промышленного комплекса России в период санкций. - Universum: Экономика и юриспруденция: электронный научный журнал. № 2. Доступ: https://cyberleninka.ru/article/n/perspektivy-razvitiya-oboronno-promyshlennogo-kompleksa-rossii-v-period-sanktsiy/viewer (проверено 28.02.2021).

Бревнов В.Г. 2016. Влияние зарубежных санкций на развитие оборонно-промышленного комплекса Российской Федерации. - Актуальные проблемы авиации и космонавтики. Т. 2. № 12. С. 479-481.

Нуреев С.В., Бусыгин Е.Г. 2017. Оборонно-промышленный комплекс России в условиях экономических санкций. - Научные труды Вольного экономического общества России. Т. 207. № 5. С. 260-279.

\section{ANTI-RUSSIAN SANCTIONS' INFLUENCE ON THE PERFORMING OF RUSSIAN DEFENSE INDUSTRY'S TASKS}

\begin{abstract}
The article is devoted to the research of the anti-Russian sanctions' influence on the performing the defense tasks, that are set by the government. Scientific approach and findings in the research domain are under consideration. The author concludes that sanctions have changed the situation in the defense industry: government's tasks are performed at a high level, nevertheless additional resources such as investments in science and modernization are required.
\end{abstract}

Keywords: sanctions, defense industry, government's defense order, import substitution, defense industry production, government support 